\title{
PERANG OBOR
}

\section{Upacara Tradisi di Tegal Sambi, Tahunan, Jepara}

\author{
Zaenal Aristanto \\ Program Manajemen Sumberdaya Pantai \\ Program Pascasarjana Universitas Diponegoro \\ Email: tok_rieza@yahoo.com
}

\begin{abstract}
Torch war is a traditional attraction that must be preserved as a local grateful expression to God on post-harvest favor. This article discusses a ceremony procession with symbolic meaning as practiced in Tegal Sambi village, Tahunan, Jepara, where communities believe that this ceremony of torch war can avoid misfortune and calamities to the village and villagers.
\end{abstract}

Key words: torch war, tradition, ceremony, village, villagers, Jepara

\section{Pendahuluan}

Kebudayaan daerah sebagai bagian dari kebudayaan nasional memberi warna pada perkembangan kebudayaan nasional dan merupakan sumber yang akan dapat memperkokoh kebudayaan nasional. Kebudayaan yang diteruskan melalui proses belajar mempunyai beberapa bagian, salah satunya yaitu upacara tradisional.

Upacara tradisional yang diwariskan secara turun-temurun oleh nenek moyang dari satu generasi ke generasi lainnya merupakan kegiatan ritual dan bertujuan memohon keselamatan, mensyukuri nikmat Tuhan dan menjalin hubungan baik dengan sesama mahluk seperti mahluk halus. Upacara tradisional muncul sesuai dengan tradisi setempat karena perbedaan tempat dan tradisi masyarakat yang bersangkutan akan melahirkan tradisi budaya yang berbeda. Salah satu bentuk upacara tradisional adalah Perang Obor di Jepara.

Perang Obor merupakan upacara tradisional yang masih dilestarikan di Desa Tegal Sambi, Kecamatan Tahunan, Kabupaten Jepara. Upacara tradisional Obor-Oboran atau Perang Obor yang dilaksanakan di Desa Tegal Sambi pertama kali dilakukan pada abad ke-16 Masehi sehubungan dengan ketokohan Ki Babadan dan Ki Gemblong dan mengalami perubahan sesuai dengan perkembangan jaman. Upacara tradisional Obor-Oboran yang dilaksanakan memiliki kekhasan dan keunikan yaitu dengan rangkaian dan dengan rentang waktu yang panjang yaitu selama tiga hari, dengan puncaknya Perang Obor yang dilakukan oleh para pemain.

Perang Obor ini merupakan atraksi budaya tradisional yang berlangsung secara turun-temurun yang harus dilestarikan karena selain merupakan tradisi budaya daerah sebagai ungkapan rasa terima kasih kepada Tuhan Yang Maha Esa atas limpahan anugerah panen kepada masyarakat setempat, juga sangat menarik untuk dinikmati oleh para wisatawan, sehingga hal ini berpotensi untuk dikembangkan dan dikemas menjadi wisata budaya yang sangat menarik.

Pesta obor diminati oleh masyarakat Jepara maupun pendatang dan dijadikan aset wisata Kabupaten Jepara dengan keterlibatan langsung Dinas Pariwisata setempat sebagai pihak penanggung jawab penyelenggaraan upacara tradisional ini. 
Puncak keramaian Perang Obor berlangsung di Desa Tegal Sambi Kecamatan Tahunan yang letaknya $\pm 3 \mathrm{~km}$ arah selatan Kota Jepara yang mampu menyedot ribuan pengunjung wisatawan domestik dan luar negeri. Beberapa permasalahan yang dapat diajukan adalah sebagai berikut.

1. Bagaimanakah prosesi upacara Perang Obor?

2. Apakah makna simbolik upacara Perang Obor?

3. Pengaruh apa saja yang berlangsung dari upacara Perang Obor?

\section{Sedekah Bumi Perang Obor}

Setiap tahun masyarakat desa setempat menggelar tradisi sedekah bumi. Salah satu acara sedekah bumi yang terkenal dalam masyarakat Jepara ialah Perang Obor. Disebut Perang Obor, sebab para peserta yang ikut acara tradisional itu menggunakan "senjata" berupa gulungan pelepah kelapa yang diisi pelepah dan dauh pisang kering. Upacara Perang Obor yang diadakan setiap tahun sekali, atas dasar kepercayaan masyarakat Desa Tegal Sambi terhadap peristiwa atau kejadian pada masa lampau yang terjadi di desa tersebut.

\subsection{Latar Belakang}

Asal mula ceritanya yaitu pada abad XVI Masehi, di Desa Tegal Sambi ada seorang petani yang sangat kaya raya dengan sebutan Mbah Kyai Babadan yang mempunyai banyak binatang piaraan, terutama kerbau dan sapi. Untuk menggembalakannya sendiri jelas tak mungkin, sehingga beliau mencari dan mendapatkan penggembala dengan sebuatan Ki Gemblong, seorang penggembala yang sangat tekun dalam memelihara binatang-binatang tersebut. Setiap pagi dan sore Ki Gemblong selalu memandikan hewan-hewan gembalaannya di sungai, sehingga binatang-binatang ternak peliharaan tersebut tampak gemukgemuk dan sehat. Tentu saja Kyai Babadan merasa senang dan memuji $\mathrm{Ki}$ Gemblong, atas ketekunan dan kepatuhannya dalam memelihara binatangbinatang tersebut.
Suatu ketika, Ki Gemblong menggembala di tepi sungai Kembangan sambil asyik menyaksikan banyaknya ikan dan udang yang hidup di sungai tersebut, dan tanpa menyia-nyiakan waktu ia langsung menangkap ikan dan udang tersebut yang hasil tangkapannya lalu dibakar dan dimakan di kandang.

Setelah kejadian ini hampir setiap hari Ki Gemblong selalu menangkap ikan dan udang, sehingga ia lupa akan tugasnya sebagai penggembala. Dan akhirnya kerbau dan sapinya menjadi kurus-kurus dan akhirnya jatuh sakit, bahkan mulai ada yang mati. Keadaan ini menyebabkan Kyai Babadan menjadi bingung, tidak kurang-kurangnya dicarikan jampi-jampi (jamu) demi kesembuhan binatang-binatang piaraannya itu, tetapi hewan-hewan itu tetap tidak sembuh.

Akhirnya Kyai Babadan mengetahui penyebab binatang piaraannya menjadi kurus-kurus dan akhirnya jatuh sakit, tidak lain dikarenakan Ki Gemblong tidak lagi mau mengurus binatang-binatang tersebut namun lebih asyik menangkap ikan dan udang untuk dibakar dan dimakannya. Melihat hal semacam itu Kyai Babadan marah besar, apalagi saat ditemui $\mathrm{Ki}$ Gemblong sedang asyik membakar ikan dan udang hasil tangkapannya. Kyai Babadan langsung menghajar $\mathrm{Ki}$ Gemblong dengan menggunakan obor dari pelepah kelapa. Melihat gelagat yang tidak menguntungkan Ki Gemblong tidak tinggal diam, dengan mengambil sebuah obor yang sama untuk menghadapi Kyai Babadan sehingga terjadilah Perang Obor yang apinya berserakan ke sana ke mari dan sempat membakar tumpukan jerami yang terdapat di sebelah kandang. Kobaran api tersebut mengakibatkan sapi dan kerbau yang berada di kandang lari tunggang-langgang dan tanpa diduga binatang yang tadinya sakit akhirnya menjadi sembuh bahkan binatang tersebut mampu berdiri dengan tegak sambil memakan rumput di ladang.

Kejadian yang tidak diduga dan sangat dramatis tersebut akhirnya diterima oleh masyarakat Desa Tegal Sambi sebagai suatu hal yang penuh mukjizat, bahwa dengan adanya Perang Obor 
segala jenis penyakit menjadi sembuh. Pada saat sekarang upacara tradisional Perang Obor dipergunakan untuk sarana sedekah bumi sebagai ungkapan rasa syukur kepada Tuhan Yang Maha Esa atas limpahan rahmat, hidayah serta taufik-Nya kepada warga Desa Tegal Sambi, dan peristiwa ini diadakan setiap tahun sekali.

\subsection{Prosesi Upacara}

Upacara tradisional Obor-Oboran merupakan upacara selamatan yang dilakukan oleh warga Desa Tegal Sambi. Upacara ini bertujuan sebagai selamatan atas keberhasilan panen dari warga desa ini yang sangat berbeda dari daerah lain. Upacara dilakukan pada malam hari dengan acara puncak Perang Obor. Upacara Perang Obor diadakan setiap tahun sekali dan jatuh pada hari Senin Pahing malam Selasa Pon di bulan Besar (Dzullhijah). Soal pemilihan waktu, dari tahun ke tahun dipilih hari kejayaan sang Petinggi (Kepala Desa). Dulu pelaksanaannya ditentukan pada bulan Dzulhijjah. Namun dalam perkembangannya dipilih waktu seusia masa panen.

Adapun rangkaian pelaksanaannya meliputi sebagai berikut.

\section{1) Pertemuan untuk Persiapan}

Mengingat Perang Obor adalah ritual adat yang sangat penting, maka Kepala Desa Tegal Sambi memimpin rapat persiapan sebagai langkah awal untuk koordinasi dan agar pelaksanaan Perang Obor berjalan sesuai rencana dan juga termasuk menyiapkan serangkaian kegiatan acara tahunan tersebut.

\section{2) Pembuatan Perlengkapan Obor}

Penduduk Desa Tegal Sambi menyiapkan segala keperluan untuk ritual adat di balai desa. Beberapa orang tampak membuat perlengkapan Perang Obor. Bahan obor yang digunakan adalah gulungan pelepah dari daun kelapa kering yang di bagian dalamnya diisi dengan daun pisang kering dengan jumlah banyak. Selanjutnya, obor diikatkan pada sebatang bambu.
Panitia sudah menyiapkan seperangkat alat berupa daun pelepah pisang dicampur dengan pelepah daun kelapa. Kedua pelepah tersebut dicampur dan diikat menjadi satu. Jumlah pelepah yang dibakar dalam perang tersebut yaitu sekitar 250-300 ikat pelepah.

\section{3) Penggantian Sarung Pusaka}

Petang harinya, Kepala Desa yang juga berperan sebagai pemimpin adat Desa Tegal Sambi memulai ritual mengganti sarung pusaka desa yang disimpan di kediamannya. Pusaka desa yang dimaksud adalah sebuah potongan kayu yang dipercaya sebagai peninggalan Sunan Kalijaga. Benda pusaka ini juga diyakini memiliki kekuatan gaib yang melindungi segenap warga desa dari segala musibah. Kepala Desa memimpin untuk memanjatkan doa kepada Yang Maha Kuasa. Setelah berdoa, Kepala Desa menyiapkan kembang setaman yang digunakan untuk ritual mengganti sarung pusaka tersebut. Setelah dicuci dengan air bunga berbagai rupa dan warna, benda pusaka dimasukkan ke sarung yang baru. Sedangkan air bekas pencucian bakal dijadikan bahan campuran obat. Sementara obat khusus yang terbuat dari minyak kelapa asli berkhasiat menyembuhkan para peserta Perang Obor yang menderita luka bakar.

Tidak banyak orang yang dapat melihat pusaka itu karena ditempatkan di sebuah ruangan khusus yang primpen (rapi dan rahasia) di rumah Kepala Desa. Petinggi menyaksikan pusaka yang baru dijamah pada prosesi buka luwur pada pagi hari. Layaknya seorang bayi, pusaka dari kayu sepanjang $40 \mathrm{~cm}$ itu dibelebet (dibungkus) kain putih berposisi menggantung di dipan kecil. Ujung atas pusaka itu didasari bantal kecil, juga bantal guling di kanan kirinya.

Pusaka itu berasal dari kayu reng masjid Demak yang diambil Ki Dawuk, leluhur Tegal Sambi, sebagai senjata dalam peperangan antara Kerajaan Demak era Raden Fatah dan Kerajaan Blambangan. Nama Dawuk yang dalam bahasa Jawa berarti abu-abu merupakan warna kuda tunggangan $\mathrm{Ki}$ Dawuk. 
Namun, saat ini makam Ki Dawuk di Tegal Sambi sudah musnah (moksa).

Sementara itu, di belakang pusaka tersebut terdapat kentungan dan beduk yang kali pertama ada di Desa Tegal Sambi. Tahun pembuatannya tak diketahui pasti, yang jelas sudah ratusan tahun.

\section{4) Ziarah Makam}

Acara berkunjung ke makam leluhur sudah berlangsung sekitar satu bulan menjelang hari pelaksanaan. Setiap Senin, Kamis dan Jumat masyarakat mengunjungi makam leluhur.

\section{5) Sesaji}

\section{a). Pemotongan kerbau}

Sesuai tradisi, sang Kepala Desa harus memotong seekor kerbau yang dijadikan sebagai hewan kurban. Setelah disembelih, darah kerbau dikumpulkan dalam sebuah wadah yang akan digunakan sebagai bahan pelengkap sesajen. Sementara dagingnya dimasak beberapa orang untuk hidangan sesajen dan kenduri warga pada malam hari sebagai bentuk rasa syukur kepada Tuhan yang telah memberikan kenikmatan.

\section{b). Sesajen}

Masyarakat Jepara menganggap kelengkapan sesaji sebagai persyaratan mutlak, sehingga mereka berusaha menyiapkaan sesaji selengkap mungkin untuk menghindari hal-hal yang tidak diinginkan.

Sesaji yang digunakan dalam upaca Perang Obor meliputi sebagai berikut.

1) Sesaji Utama berupa kepala kerbau.

2) Sesaji Pelengkap, sebagai berikut.

a) Nasi, berupa sega golong, tumpeng dan ketupat.

b) Lauk pauk berupa dekem ayam, panggang ayam dan telur.

c) Sayur berupa urab atau gudhangan dan jangan kunci kelor.

d) Arang-arang kambang terdiri dari cengkaruk ura dan cengkaruk gimbal. e) Lepet terbuat dari beras ketan yang dicampur kelapa muda dan diberi garam yang dibungkus daun kelapa muda kemudian dikukus.

f) Bubur abang putih terbuat dari beras yang dicampur dengan santan dan garam, untuk yang berwarna merah diberi gula jawa.

g) Jajan pasar terdiri dari makanan yang dijual di pasar yaitu kerupuk, jambu merah, mentimun, tape dan gethuk.

h) Buah yang digunakan berupa pisang raja setangkep.

i) Bunga kembang yang digunakan berupa kembang mawar, melati dan kanthil atau yang lebih dikenal dengan kembang setaman.

j) Kelapa hijau.

k) Bahan makanan mentah berupa beras, gula kopi, bumbu, mpon-mpon yang dimasukkan dalam kasung.

I) Sawanan merupakan air bekas mencuci pusaka.

\section{6) Pemberangkatan Sesaji}

Semua sesaji yang sudah disiapkan dan lengkap dibawa ke rumah Kepala Desa. Satu porsi sesaji diletakkan di ruang penyimpanan pusaka. Sedangkan sisanya didistribusikan ke berbagai tempat, antara lain ke Makam Mbah Tegal sebagai sesepuh Dusun Tegal Sambi serta di perempatan jalan dan batas desa. Selanjutnya, warga berkumpul di masjid desa. Mereka menggelar kenduri dan doa bersama agar pelaksanaan Perang Obor berjalan lancar.

\section{7) Pagelaran Wayang Kulit}

Tradisi yang tak dapat ditinggalkan adalah pagelaran wayang kulit, yang dilaksanakan dua kali yaitu pada malam sebelum Perang Obor dan sebelum pelarungan sesaji, yang merupakan syarat pelarungan atau sebagai iringan pengantar pada saat pelarungan sesaji. Wayang kulit digelar hingga semalam suntuk.

\section{8) Puncak Ritual, Perang Obor}

Puncak ritual Perang Obor sebagai ungkapan syukur atas segala karunia Sang Pencipta dimulai pada malam hari. Pada 
ritual ini Kepala Desa melangkah menuju lokasi. Perang Obor selain melibatkan warga setempat juga disaksikan ribuan penonton dari berbagai daerah, bahkan para wisatawan. Setiap warga Desa Tegal Sambi memang berhak menjadi peserta asalkan memiliki keberanian menghadapi risiko mengalami luka bakar. Sedangkan warga luar desa tak boleh ikut karena dikhawatirkan mendapat sial. Dengan disaksikan ribuan mata, Kepala Desa kemudian menyuruh warga menyalakan Obor-Obor. Selanjutnya, Obor-Obor yang menyala itu dibagikan kepada para peserta dan Perang Obor pun dimulai.

Kemudian para peserta tampak saling memukul dengan menggunakan obor yang membara. Memang unik dan menarik, namun mendebarkan. Ini mengingat para peserta dalam memainkan obor masing-masing terlihat bersungguhsungguh seperti berperang. Mereka percaya bahwa kesungguhan itu sebagai simbol memerangi kejahatan dan mengusir penyakit. Dengan demikian, desa mereka bebas dari segala marabahaya. Dalam ritual tersebut, mereka juga terlihat saling kejar hingga sampai rumah Kepala Desa. Para peserta kemudian kembali ke perempatan jalan dan berakhir di Balai Desa. Malam itu, jalan-jalan di desa menjadi lautan api. Ritual yang lebih mirip pertandingan bela diri ini baru berakhir bila seorang peserta tinggal sendirian atau tak lagi memiliki lawan yang akan dihadapi. Namun, sang pemenang tak akan mendapatkan hadiah tertentu kecuali kebanggaan dan reputasi diri.

Untuk memeriahkan acara, usai tradisi ritual Perang Obor yang digelar di perempatan jalan utama di Desa Tegal Sambi, maka didukung acara ini dengan panggung hiburan dangdut.

\section{9) Penyembuhan Luka}

Ritual Perang Obor telah berakhir dan saatnya menyembuhkan luka bakar yang dialami sejumlah peserta akibat terkena sambaran api. Namun, mereka tak perlu khawatir. Soalnya, Kepala Desa telah menyiapkan ramuan khusus yang telah diraciknya. Dengan sedikit olesan, luka- luka mereka pun hilang tanpa bekas. Menurut sejumlah warga, dari tahun ke tahun, ritual Perang Obor selalu berlangsung lancar. Bahkan, sulit dijumpai sejumlah peserta yang cedera serius, apalagi sampai dilarikan ke rumah sakit.

\section{0) Pagelaran Wayang Kulit}

\section{Sesudah Perang Obor}

Setelah Perang Obor usai diadakan pagelaran wayang kulit di tempat yang sama.

\subsection{Makna Simbolik Sesaji Upacara Perang Obor}

1). Kepala kerbau sebagai simbol rasa syukur dan bermakna sebagai penolak bala.

2). Sega Golong, maknanya adalah dengan kebulatan tekad dan hati yang teguh apa yang dicita-citakan akan berhasil atau terlaksana.

3). Tumpeng, yang berwarna kuning, dari bentuknya secara vertikal berarti untuk menggambarkan hubungan manusia dengan Tuhannya, sedangkan bagian bawah yang bentuknya melebar melambangkan hubungan manusia dengan sesamanya.

4). Kupat, atau ketupat, mengandung makna meminta maaf atas semua kesalahan.

5) Dekem atau Ingkung Ayam menjadi lambang bagi kelakuan pasrah kepada kekuasaan Tuhan.

6) Bubur Abang Putih mempunyai arti sebagai lambang untuk menghormati asal usul kejadian diri manusia yang terdiri dari merah (unsur ibu) dan putih (unsur ayah).

7) Arang-arang Kambang, terdiri dari cengkaruk ura dan cengkaruk gimbal yang mempunyai makna untuk menghormati yang Mbau Rekso (penjaga gaib) Kali Wiso yaitu Mbah Tunggal Wulung.

8) Jajan Pasar terdiri dari 5 (lima) macam yang menggambarkan hari pasaran 
Jawa yaitu Pon, Wage, Kliwon, Legi dan Paing.

9) Pisang Raja, melambangkan harapan agar kita diberi kehormatan, kewibawaan dan kebijaksanaan dalam menjalani kehidupan seperti seorang raja.

10) Kembang, mempunyai makna sebagai perwujudan kebaktian kepada nenek moyang atau pepunden dengan tujuan dijauhkan dari gangguangangguan.

\section{Pengaruh Perang Obor}

\subsection{Pengaruh Langsung}

1)Pelestarian nilai nilai tradisi yang hidup dan berkembang di dalam masyarakat agar tidak punah terkikis oleh budaya modern.

2)Sebagai pewarisan nilai-nilai luhur yang terkandung dalam perlambang atau makna eksplisit yang terkandung dalam pelaksanaan tradisi Perang Obor.

3)Dalam bidang ekonomi, masyarakat akan mendapatkan keuntungan dengan berjualan makanan atau membuka tempat parkir kendaraan bagi para penonton.

\subsection{Pengaruh Tidak Langsung}

1) Memberikan keyakinan pada masyarakat pelaku Perang Obor bahwa ada kekuatan di luar dirinya yang mengatur jalannya kehidupan manusia di dunia, yaitu Allah SWT.

2) $\mathrm{Di}$ bidang ekonomi, masyarakat Desa Tegal Sambi mempunyai keyakinan jika melaksanakan upacara sedekah bumi maka keadaan ekonominya akan meningkat.

3) Di bidang budaya, tradisi ini lebih memperkaya budaya daerah.

4) Di bidang sosial, Perang Obor akan mempererat ikatan persaudaraan masyarakat desa.

\section{Penutup}

Upacara Perang Obor yang dilaksanakan di Desa Tegal Sambi, Kecamatan Tahunan, Kabupaten Jepara diadakan sekali dalam setahun, yaitu pada bulan Apit antara Hari Raya Idul Fitri dan Hari raya Idul Adha, atau antara bulan Syawal dan bulan Dzulhijah, yang pelaksanaannya memilih waktu pada hari Senin Pahing malam Selasa Pon.

Tujuan Perang Obor adalah untuk mengusir segala macam penyakit maupun menolak bala atau bahaya, segala macam gangguan dan berfungsi sebagai pengungkapan rasa syukur masyarakat desa kepada Tuhan Yang Maha Esa atas rahmat yang diberikan oleh-Nya.

Perayaan sedekah bumi dimulai dari pembukaan sampai dengan upacara puncak selama selapan atau kurang lebih 35 (tiga puluh lima) hari, tetapi dalam selapan hari tersebut, 7 (tujuh) hari terakhirlah yang penting atau acara yang sakral.

Masyarakat Desa Tegal Sambi memaknai tradisi Perang Obor ini sebagai suatu ritual yang harus dilaksanakan karena masyarakat telah melaksanakan secara turun-temurun dan percaya bahwa dengan melakukan ritual tersebut maka desa akan terhindar dari sengkolo atau mara bahaya dan masyarakat desa memperoleh berkah dari Allah SWT.

\section{DAFTAR PUSTAKA}

Ariyanti, Hendri. 2003. Fungsi dan Makna Simbolis yang terkandung dalam Upacara Sedekah Laut, di Kabupaten Cilacap. Yogyakarta: Prodi Pendidikan Bahasa Daerah.FBS. Universitas Negeri Yogyakarta

Bastomi, Suwaji. 1992. Seni dan Budaya Jawa. Semarang: IKIP Semarang Press.

Brawidjaya, W. 2000. Upacara Tradisional Masyarakat Jawa. Jakarta: Pustaka Sinar Harapan

Herusatoto, B. 1983. Simbolisme dalam Budaya Jawa. Yogyakarta: Hanindita.

2002. Selayang Pandang Pesta Rakyat. Jepara: Dinas 
Sabda, Volume 6, Nomor 1, April 2011: 88-94

Perhubungan dan Periwisata Kabupaten Jepara.

Muhibbuddin, Muhammad. 2008. Tradisi Menghidupkan Obor Sejarah Nenek Moyang dalam http://www.moxeeb.wordpress.com/ 2008/08/05/perang-obor/. (diakses 25 Mei 2009).

Sutrisno, Sulastin, dkk. 1991. "Kegunaan Folklor sebagai Sumber Sejarah Lokal Desa-desa di Indonesia," dalam Bahasa, Sastra, Budaya. Yogyakarta: Gajah Mada University Press.

Turner, Victor. 1982. The Forest of Symbol. Ithaca and London: Cornell University Press.

www.gojepara.com/id/torch-war.html. (diakses 25 Mei 2009).

www.jeparakab.go.id/index.php/component /option,com_events/ltemid,29/agid, 16/day,13/month,4/task,view_detail/ year,2008/. (diakses 25 Mei 2009).

www.wisatabenewskp.blogspot.com/2005/ 11/kabupaten-jepara.html. (diakses 25 Mei 2009). 